\title{
European Central Bank -Conventional And/Or Unconventional Instruments For Monetary Policy*
}

\author{
Klimentina POPOSKA ${ }^{* *}$ \\ Elena MIHAJLOSKA ${ }^{* * *}$ \\ Iskra STANCHEVA-GİGOV****
}

\section{ABSTRACT}

The mechanisms the monetary policies have failed to foresee, not to mention to prevent the 2008 Financial Crisis (FC). Moreover the burst of the crisis has challenged the market mechanism for maintaining market liquidity, financial stability and risk management. The European Central Bank (ECB) has played crucial role in the aftermath of the 2008 FC for maintaining the market liquidity. The measures taken in the post crisis period were conflicting with the basic foundations of the monetary policy of EMU, but prevented the collapse of the financial market. While the ECB has successfully controlled inflation levels and maintained market liquidity failed to spur growth as expected. The paper discusses the challenges that emerge from these policy measures and provides a recommendation for future actions. Moving away from these measures has been emphasized as one of the main challenges with exiting too early and too late being equally dangerous. The discussion continues with the analysis of the effects and implication in practice of ECB Instruments and their future utilization. The question rises whether the monetary policy should go back to the conventional instruments or maintain excess liquidity and operate the system through parallel adjustments to the deposit facility rate and the rate on the main refinancing operations.

Keywords: European Central Bank; Instruments forMonetary policy; EU; Unconventional measures; Financila Crisis

Jel Classification: E52; E58.

\footnotetext{
* This article was presented as a paper at the IV. International Symposium on Accounting and Finance in Ohrid, Macedonia, July 3-5, 2017.

** Ph,D, Institute of Economics-Skopje, University Ss. Cyril and Methodious-Skopje, Republic of Macedonia. E-mail: klimenti@ek-inst.,ukim.edu.mk

${ }^{* * *}$ MSc, Elena Mihajloska, Coordea Outsourcing. E-mail: mihajloskae@gmail.com

**** $\mathrm{Ph}$,D, Institute of Economics-Skopje, University Ss. Cyril and Methodious-Skopje, Republic of Macedonia. E-mail: iskra@ek-inst.,ukim.edu.mk
} 


\section{INTRODUCTION}

The economy is still recovering from the 2008 Financial Crisis (FC) which no one predicted, not to mention failed to prevent. What happened and where or why did the monetary policy flounder?

The 2008 FC has emphasized the flaws of the monetary policy and raised a critical eye upon the efficiencies of the policy measures. The main goal of the monetary policy is maintaining price stability through steering short term interest rates. The ECB aims at inflation rates of below, but close to, $2 \%$ over the medium term using the instruments of open market operations, standing facilities and the minimum reserves. Additionally, the monetary policy aims to increase economic growth and maintain high level of employment.

However, the analysis in this paper will show that the burst of the crisis was not preceded by high inflation rates which directly question the effectiveness of this approach for predicting and/or preventing bubble burst and financial crisis. Another question rising from the events following the burst of the FC is how successful has been the monetary policy in sustaining growth in both stable and unstable conditions. Have we been living in a stagnant global economy where growth has been spurred solely by credit?

The emerged situation has forced the monetary policy to apply unconditional measures to avoid liquidity trap. During the Financial crisis (2007/2008) the ECB lowered the interest rates to historically low degree and increased balance sheet's size to unprecedented levels. Both of these measures are conflicting with the foundation rules of the European Monetary Union (EMU) and have been openly criticized. Nevertheless, they have also emerged as inevitable actions in the post-crisis period.

In practice, the measures proved to be very successful in provision market liquidity when governments and the banking sector failed, but have been less successful in initiating growth and revival of the economy. Low interest rates have not translated in more spending and higher investments in the real economy, while increased size of ECB's balance sheet has posed additional challenges of keeping central banks independency. Exit from these unconventional policy measures have emerged as the major challenge for the future of EMU.

The paper at hand, firstly, provides a better understanding of the mechanisms used by the monetary policy prior the crisis which are also analysed through the prism of post crisis events. This section highlights the potential red alarms that pay have signalled the 2007/2008 events like the sudden growth in household consumption while decreasing saving rate. Second, the unconventional measures of the monetary policy are explained, and the reasons for their implementation. Special focus is placed on analysing their effectiveness in maintain liquidity on the market and initiating growth in the post-crisis period. However, the biggest challenge emerging from the analysis is IF and WHEN should the monetary policy go back to the conventional policy measures. Have we learned anything from the crisis and can we build mechanisms that will effectively not only maintain price stability but initiate real economic growth? The paper at hand 
provides several stance for the way ahead that are combination of the conventional and nonconventional measures and vouches for more contextual approach when it comes to spurring economic growth through innovation and entrepreneurship.

\section{ECB MONETARY POLICY: PRACTICAL ISSUES}

Maintaining price stability is expected to result in the accomplishment of the two consecutive goals, to increase economic growth and maintain high level of employment. Deviations, both below and above the $2 \%$ inflation rate are consider inconsistent with price stability and should be a signal for market turbulences. Graph 1 shows that the inflation calculated by the Harmonised Index of Consumer Prices (HICP) Index across all EU member in the period 2004-2016.

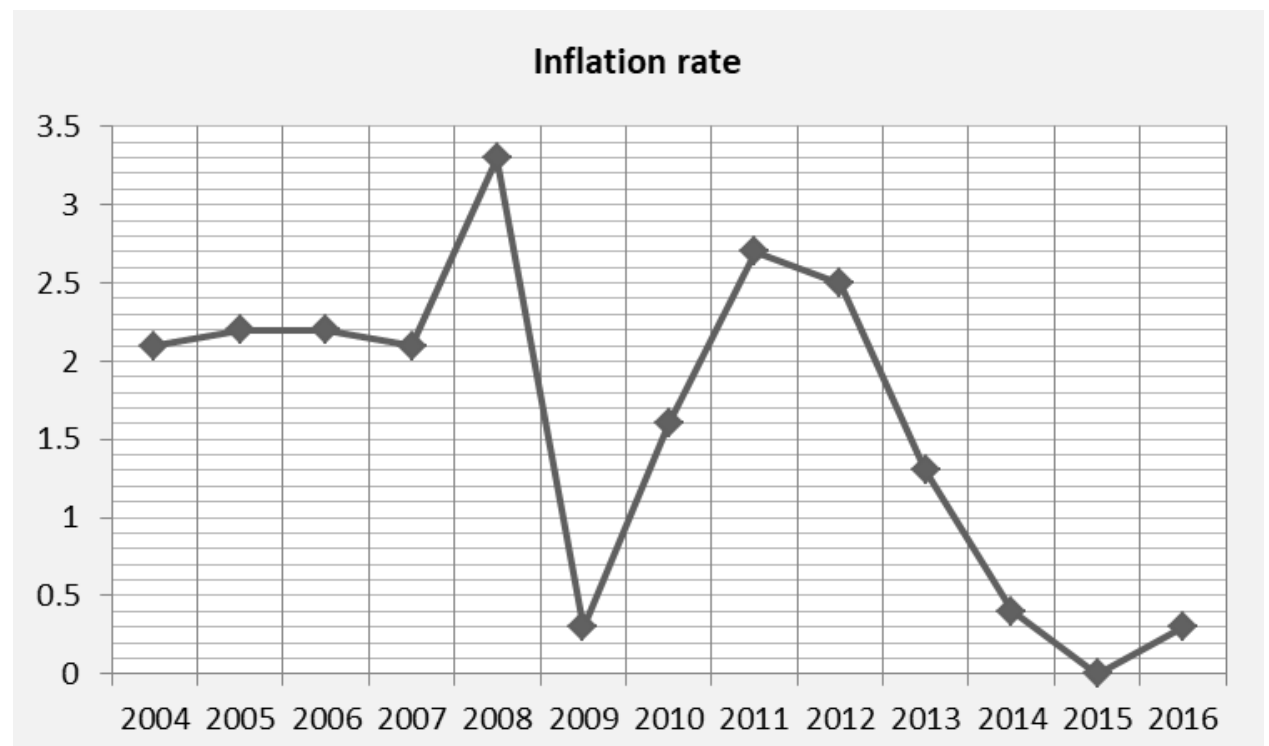

Source: Statistical data warehouse of ECB, http://sdw.ecb.europa.eu/home.do, Accessed on

Graph 1. Inflation rate, EU area, 2004-2016

Analyzing Graph 1 we can perceive that the countries has been fairly consistent through 2004-2007 not even signalling the burst of the 2008 Financial Crisis.

At the same time, asset prices and credit, both, boomed. Despite the decreasing saving rate, the household consumption continued to grow with an increase in mortgage debt 30\% larger than the rise in other consumption debts (Mian and Sufi, 2008). During these years the policy was almost always accommodative which can lead to massive increases in asset prices and credit aggregates without triggering movements in consumer price inflation (Cecchetti, 2011). 


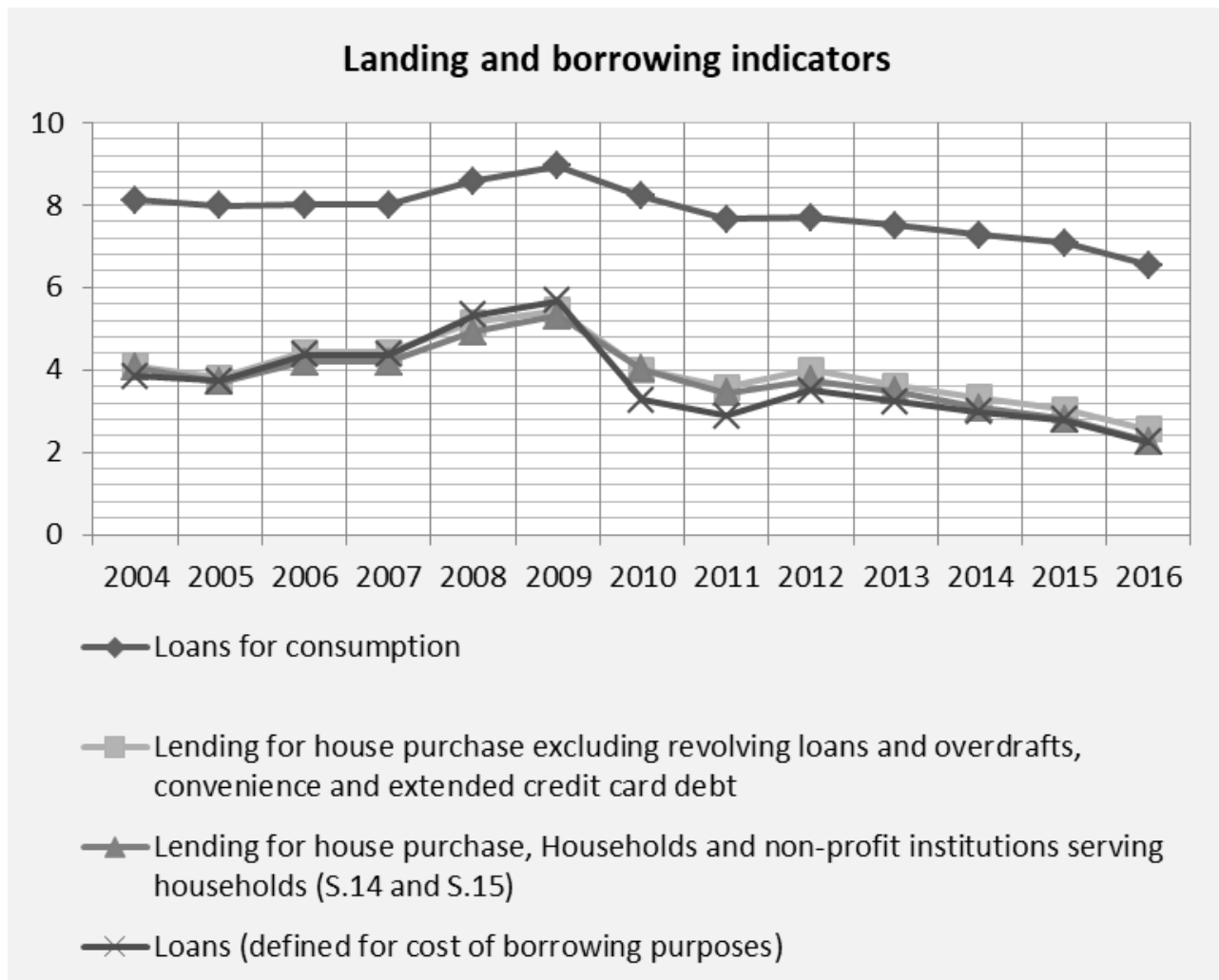

20/10/2016

Source: Statistical data warehouse of ECB, http://sdw.ecb.europa.eu/home.do, Accessed on

Graph 2. Developments in loans in EU in period 2004-2016

As seen in Graph 2, the debt accumulated in the years prior the crisis leading to the burst of the 2008 FC. The problem with monetary policy's focus on price stability through the prism of inflation rate was that temporary inefficiencies, such as asset price bubbles, were considered possible, but the majority view was that monetary policy could do little to counteract such developments. The $2008 \mathrm{FC}$ has revealed the flaws of this approach and while, the monetary policy was successful in maintaining low inflation levels after the hit of the crisis, it did little if anything for preventing the 2008 FC.

\section{CONVENTIONAL AND UNCONVENTIONAL INSTRUMENTS FOR MONETARY POLICY}

For steering the monetary policy, the ECB utilizes range of monetary policy instruments such as open market operations, provides standing facilities and requires credit institutions to hold minimum reserves. Another objective of the range of instruments available to the ECB is to influence market interest rates and liquidity in the banking system and thereby signal the direction of monetary policy.

The ECB instruments mainly consist of bank refinancing facilities, mostly in the form of reverse transactions granted against eligible collateral: up until the financial crisis, they comprised the short term (Main refinancing operations (MROs) one week) and the long term refinancing operations (LTROs, three months), fine tuning operations 
(non-standard duration, also including collection of fixed-term deposits and foreign exchange swaps), issuance of ECB debt certificates (to drain liquidity), and standing facilities at the disposal of banks to draw or deposit funds overnight to smooth liquidity (the marginal lending and deposit facility).The MROs are the main monetary policy instrument, and the interest rate charged on these operations is the key official reference rate.

In order to ensure the maintenance of price stability over the medium term, ECB beside the standard instruments was compelled to introduce non-standard policy instruments. The critical issue was sustaing the transmission mechanisms for maintaining the liquidity of money markets ability of the banking sector to lend to the real economy. The measures were focused in two main areas: lowering interests rates and expansion of liquidity operations in terms of frequency and maturity as well as extension of the list of eligible collateral (Weber, 2010: p.2).

First, the ECB turned towards lowering interest rates to unprecedented levels. The low interest rates are expected to discourage savers to further save money and initiate spending. Higher demand would initiate investments and result in economic growth. In practice, none of the expected happened. Namely, lowering interest rates had little effect on spending due to the tight margins (Graph 3).

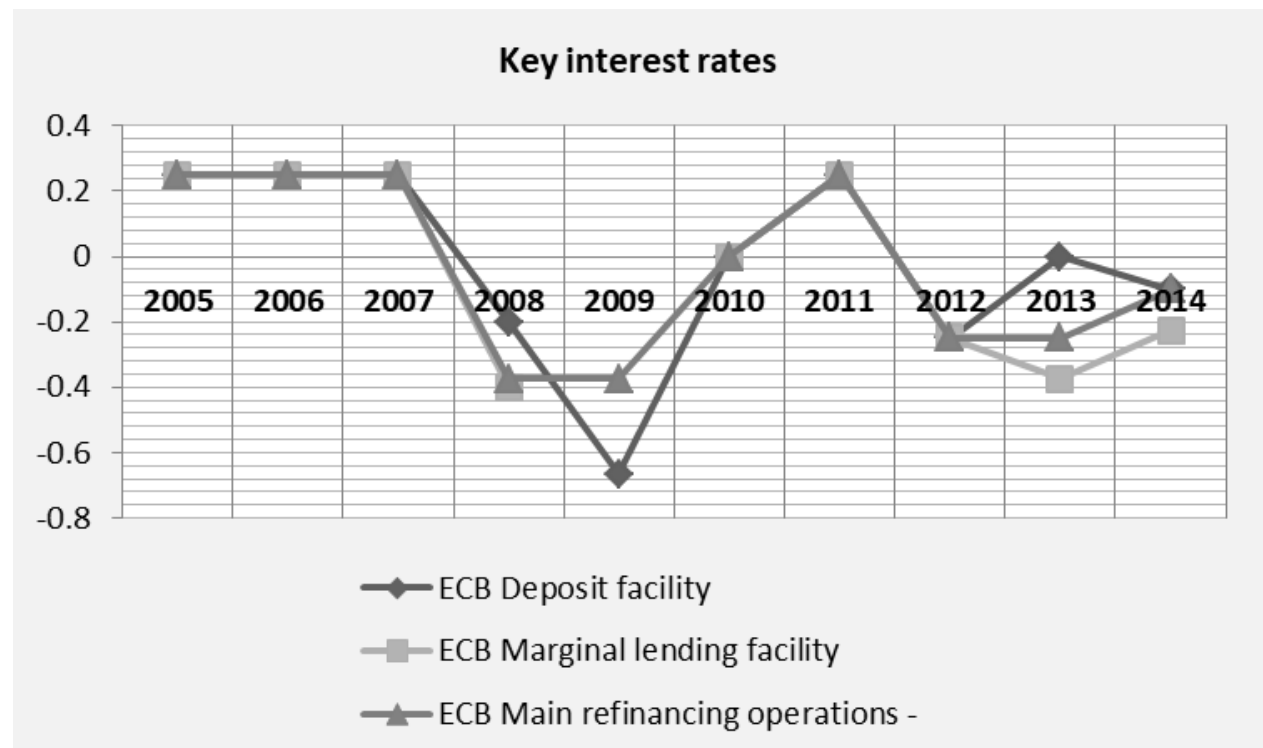
$20 / 10 / 2016$

Source: Statistical data warehouse of ECB, http://sdw.ecb.europa.eu/home.do, Accessed on

Graph 3. Standing facilities (key interest rates), EU-area, 2005-2014

Real interest rates did not fall enough, because nominal interest rates cannot be reduced below zero, the so-called zero lower bound problem (Raghuram, 2013: p.5). This resulted in the so called "liquidity trap" introduced first by John Maynard Keynes in the 1920s. People discouraged to save by too low interest rates will not rush into spending but will instead hoard money ceasing investment altogether. The expected demand for loans doesn't happen; interest rates remain low causing further decline in 
prices. The situation can evolve in a dangerous deflationary spiral (Hayes, 2016a). For that reason the ECB alongside banks in Sweden, Denmark and Switzerland took a step further into negative interest rate policy (NIRP) making savers to pay interest for deposits kept in banks. The ultimate goal is to completely discourage saving and hoarding money and encourage lending and investment (Hayes 2016b). However, the ECB must be careful with such drastic measures and take into account that the effect of NIRP will directly impact only amounts of reserves above some threshold. The real challenge for the monetary policy has been stimulating growth in which they have achieved little, if any, success. While ultra-low interest rates have sustained inflation in the post crisis years, their efficiency in initiating and sustaining growth has been questioned.

Low interest rates were accompanied by additional policy measures aiming to restore the liquidity of the market. The ECB maintains the liquidity of the European market through the main refinancing operation (MRO) and three-month liquidity referred to as the long term refinancing operations (LTRO). However, after the hit of the FC, the ECB extended the maturity period of LTRO to three years and also introduced targeted long term refinancing operations (TLTRO) (ECB, 2014a). While rates of marginal lending facility and deposit facility remained close to zero LTROs reached unprecedented levels at the expanse of MROs (Graph 4).

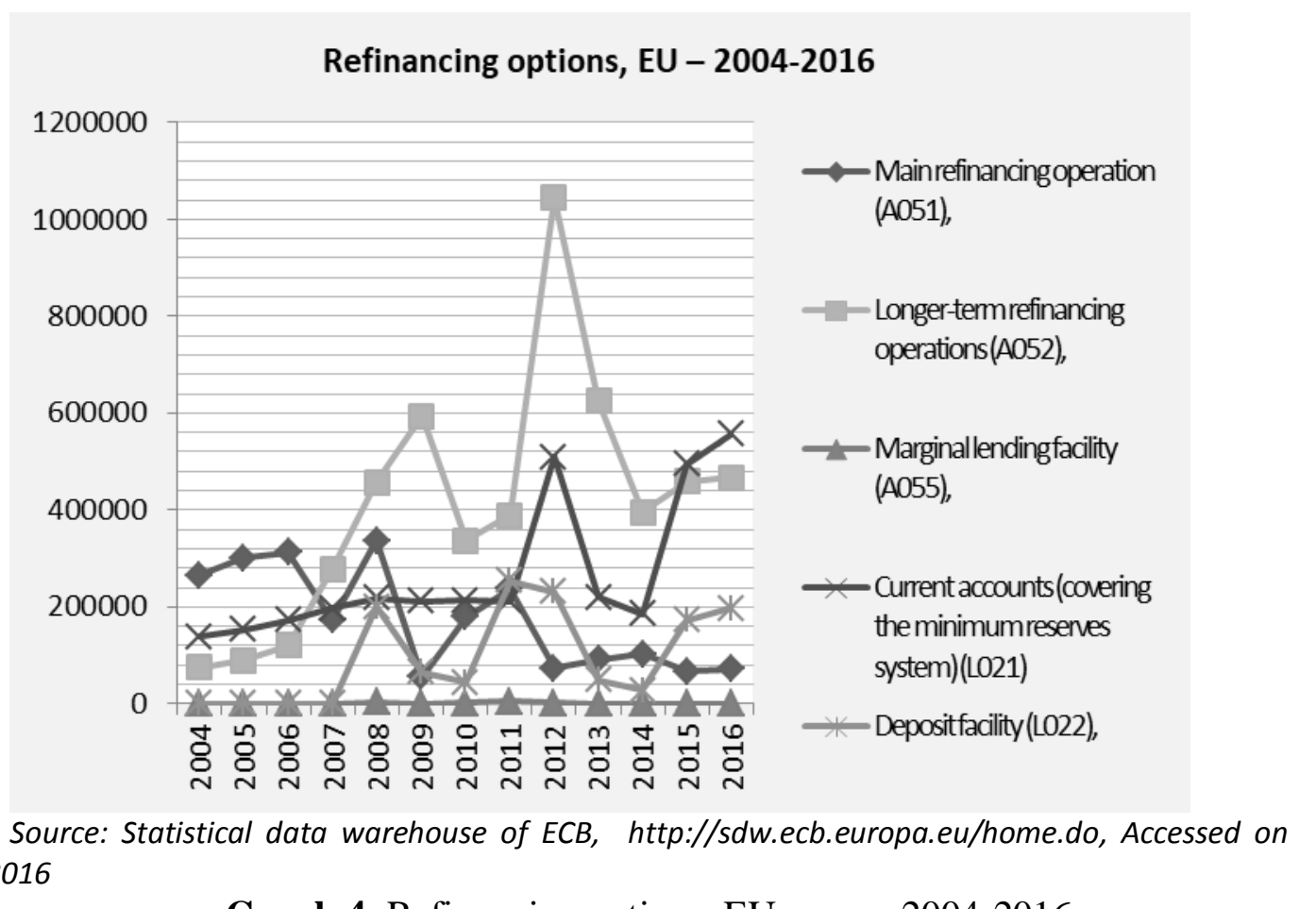

Graph 4. Refinancing options, EU - area, 2004-2016

The graph clearly shows exponential increase of long-term refinancing operations particularly in the years following the hit of the crisis. By replacing banks' intermediate-maturity wholesale market borrowing with longer-term refinancing operations, the ECB fully accommodated the banks' demand for liquidity in an elastic manner. In addition, the ECB also expanded the list of eligible collateral, so that banks 
could more easily liquefy their balance sheets and mobilise assets (Coeuré, 2013: p.2). Actually, central bank balance sheet policy has shown itself to be a powerful and flexible instrument during crisis times (Graph 5).

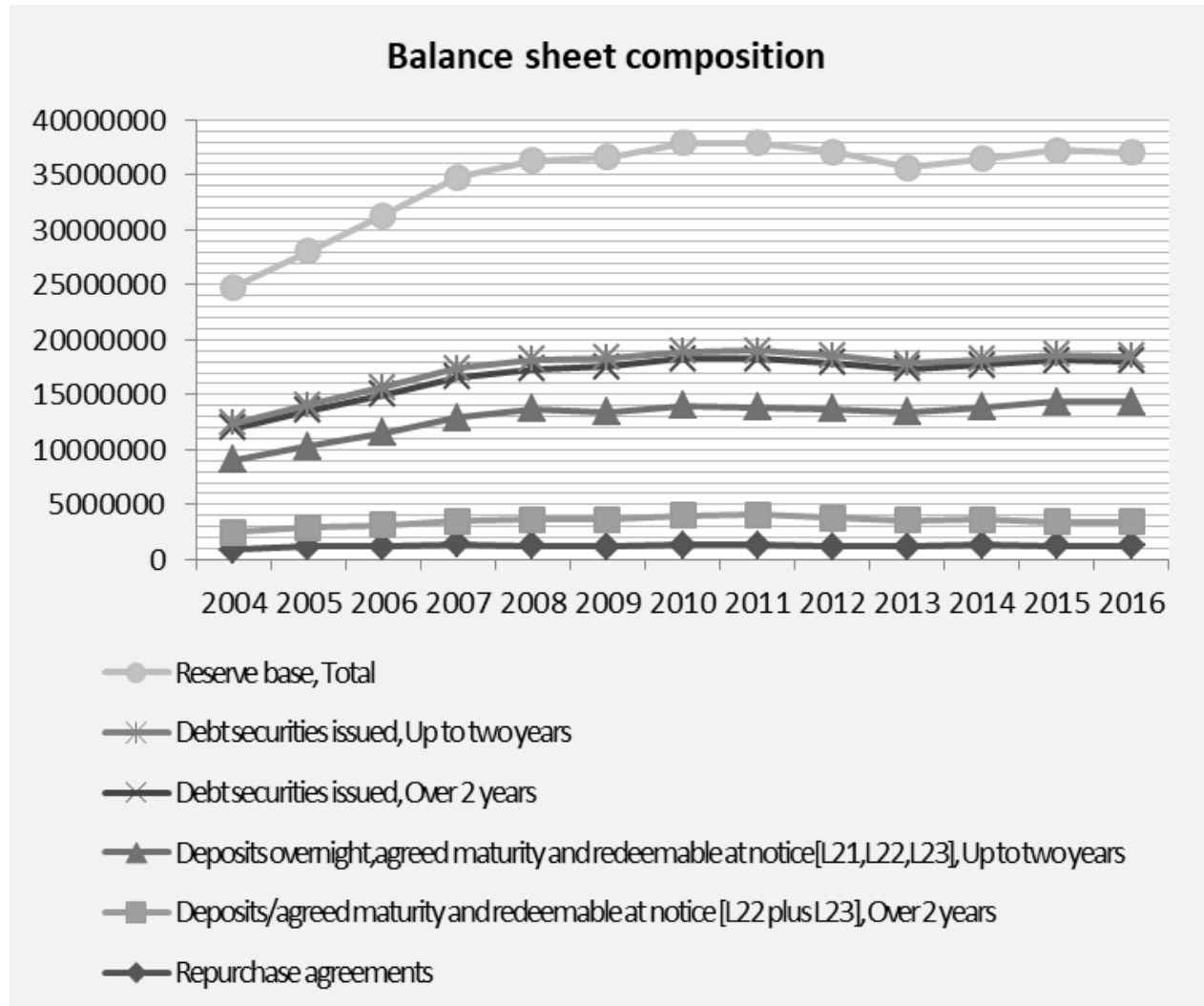

20/10/2016

Source: Statistical data warehouse of ECB, http://sdw.ecb.europa.eu/home.do, Accessed on

Graph 5. Balance sheet size and composition, ECB, 2004-2016

Graph 5 shows the change in both size and composition since 2004 through increasing of maturity and riskiness of their assets. The ECB, in one of its Economic Bulletin (2015b) clearly states that the use of the central bank balance sheet over time has marked a transition from reactive, or passive, on-demand liquidity provision with, to active or controlled deployment in an effort to affect broad financial conditions. Cecchetti, (2011) argues that this aggressive and flexible use of central bank balance sheets was instrumental in preventing a collapse of the global financial system and the global economy. Raghuram (2013) agrees that lending long term with the extension of the accepted collateral restored liquidity to a world financial system that would otherwise have been insolvent based on prevailing market asset prices.

\section{EFFECTS AND PRACTICAL IMPLICATION OF ECB INSTRUMENTS}

ECB's lowering of the interest rates send a signal to commercial banks to lower their rates as well aiming to spur the demand in what appeared to be a stagnant economy. However, as we saw in above discussion, this did not happen implying that the nature of the crisis may need more specific measures rather than a broad low rates 
policy. Firstly, savers with end-of-working-life savings objectives who have suffered a loss of savings will only put more money aside as interest rates fall in order to meet the savings they think they will need when they retire (Raghuram, 2013:p.6) Second, low interest rates can cause overinvestment in areas where asset prices or credits are particularly sensitive to low interest rates and unanchored by factors such as international competition (Raghuram, 2013: p.11). This again will create a false and just a temporary movement in the economy initiated by selective sectors. Real growth and increase in the economic activity is created by innovative and disruptive ideas commercialised through entrepreneurship. However, in the face of the market uncertainty after the prolonged recession entrepreneurs postponed the realisation of their business ideas for times when there will be a clear increased source of effective demand (Johnston, 2015). Additionally, in post crisis period even healthy firms do not invest in the bust, not because they face a high cost of capital, but because there is uncertainty about where, when, and how, demand will reappear. The lack of capital as major obstacle for start-ups, especially after the credit crunch, is only superficial understanding of the problem. Research during the recession found that SMEs intentionally avoided further indebtedness and pursued investments for growth only when there had sufficient internally generated funds (Kelley et al 2011; Geho et al 2013). Policy makers have failed to take into account the contextual effect of the postcrisis unstable environment on potential entrepreneurs (Poposka et al. 2015).

On the other side we have witnessed global slowdown of the economy. The underlying problem is insufficient investment demand, across the world, to absorb all the savings available in the economy. The 2008 FC has just emphasized this situation. The argument here is that low interest rates are not the solution, nor the problem, but a symptom of global excess of savings over profitable investments. Policy measures must analyse today's slow economy on a broader scale tacking both the long- and short-term drivers of lack of demand (Draghi, 2016). Recently, the FEDs have increased their interest rate for the first time since the hit of the crisis which may signal an increase in interest rates by the ECB as well. Inflation rate has been held too low for too long by the ECB risking losing credibility as businesses and households lose faith in its policy moves. At the International Monetary Fund (IMF), ECB's President Mario Draghi announced an increase in inflation rate towards 1 percent, and later on, above 1 percent, by year end or the first months of next year (Koranyi and Strupczewski, 2016).

\section{FURTHER UTILIZATION OF THE ECB INSTRUMENTS- CONVENTIONAL OR UNCONVENTIONAL POLICY INSTRUMENTS}

Many have criticized the adoption of unconventional measures. Firstly, the expansion of ECB balance sheet blurs the distinction between monetary and fiscal policy and puts the central bank's financial strength at risk. However, we have to admit that without the nonstandard measures of ECB, the market would have been in a liquidity trap. The question now is not whether the ECB should have engaged in unconventional policy measures, but whether it should go back to the traditional ways of functioning and if yes, HOW and WHEN? Weber (2010) warns that there is a huge risk of both exiting too early and in exiting too late with the second one being more likely as inflationary expectations have not been reached yet. Maintaining the 
accommodative policy stance for too long may risk a de-anchoring of inflation expectations, which is costly to reign in.

The ECB can return to conventional monetary policy by either rising interest rates or reducing balance sheet's size. If interest rates go up lenders benefit, while borrowers lose with borrowers being far worse off than lenders benefit. This is even more severe when we turn to governments as borrowers. Namely, low nominal rates have reduced the funding cost of governments and exiting from unconventional policy measures rates would increase debt-to income ratio leading towards potential country's default for some governments. The heterogeneity of the member states makes the decision even more difficult. In contrast, keeping rates this low for a longer period of time may hurt the structure of the real economy by compromising the market mechanisms in efficiently allocating resources (De La Dehesa, 2013).

Reducing the size of balance sheets is another option for returning to standard monetary policy, although not without challenges. If the ECB decides to cut down reserves by lowering down the interest rate on deposits it risks initiating inflation. On the other side, if it keeps balance sheets same size for a longer period, banks will keep reserves at the central bank due to attractive interest rates on deposits decreasing the funds available for lending into the real economy and hampering growth (Sibert, 2013). Another aspect that must be taken into account when reducing reserves is again the heterogeneity of the countries in regard to their sovereign debts. This may imply that the exit strategy will have to follow a clear end of the sovereign crisis (Wyplosz, 2013).

Third stance vouches against going back to conventional policy measures arguing that conventional monetary policy did not ensure lasting financial and economic stability. Coeure (2013: p.3) poses the question if maybe the ECB should maintain excess liquidity and operate the system through parallel adjustments to the deposit facility rate and the rate on the main refinancing operations.

\section{CONCLUSION AND RECOMMENDATIONS}

The paper has provided some key lessons and directions for future adaptations of the monetary policy measures. First learning point is that accommodative monetary policy has led to massive increases in asset prices and credit aggregates without triggering movements in consumer price inflation (Cecchetti, 2011). For that reason we need a more symmetrical monetary policy in terms of better risk assessment with regard to their implications for price stability on the long run.

The paper at hand gave an overview of ECB's response to the crisis and better understanding of the unconventional policy measures. Lowering of the interest rates and increase of balance sheet size has been crucial in avoidance of the market liquidity trap and prevention of collapsing financial market. The ECB, acting as lender of last resort, has taken a bigger role than focusing solely on price stability.

However, the measures still have their challenges and the future is still very uncertain. Despite the excess liquidity, risk aversion remains high, since investors don't know when and how real demand will reappear. The biggest challenge has been exit from unconventional policies with exiting too early and too late being equally likely. 
Interest rates have been kept too low for too long risking de-anchoring of inflation expectations, which is costly to reign in.

The views for future recommendations are distinctive. Arguments have been made in favor of the unconventional policy measures suggesting that maintaining excess liquidity and operating the system through parallel adjustments to the deposit facility rate and the rate on the MROs becomes a common practice of the ECB. The need for more symmetrical monetary policy and more prudential regulations has been emphasized. The EMU needs more efficient risk management with the right incentives and better risk assessment of implicit risks stemming from lively money and credit growth, booming asset markets and decreasing risk premiums. Safeguarding central bank independence has also been pointed out as another crucial recommendation for, both, avoiding the moral hazard problem and successful exit from the unconventional policy measures.

\section{REFERENCES}

Cecchetti, S. G. (2011, October). Monetary policy lessons learned from the crisis and the post-crisis landscape. In SEACEN-CEMLA Conference.

Cœuré, B. (2013, May). Where to exit to? Monetary policy implementation after the crisis. In speech at the 15th Geneva Conference on the World Economy:"Exit strategies: time to think about them", Geneva (Vol. 3).

De La Dehesa, G. (2013). Tapering and exiting from present monetary policies. ECB, Monetary Dialogue, Directorate General For Internal Policies, Policy Department A: Economic And Scientific Policy, Available at: http://bookshop.europa.eu/en/exit-strategies-and-the-impact-on-the-euro-areapbQA0214086/, Accessed on: 26 December, 2016

Draghi, M. (2016, May). Addressing the causes of low interest rates. Introductory speech at a panel on "The future of financial markets: A changing view of Asia" at the Annual Meeting of the Asian Development Bank. Available at: https://www.ecb.europa.eu/press/key/date/2016/html/sp160502.en.html, Accessed on 23 December, 2016

ECB (2014a, June). ECB announces monetary policy measures to enhance the functioning of the monetary policy transmission mechanism. Available at: https://www.ecb.europa.eu/press/pr/date/2014/html/pr140605_2.en.html, Accessed on: 26 December, 2016

ECB (2014b). Economic and monetary developments. Economic Bulletin, Issue 4

Geho, P. R. and J. Frakes (2013). Financing for small business in a sluggish economy versus conflicting impulses of the entrepreneur. Entrepreneurial Executive 18: 89-101.

Hayes, A. (2016a, March). Quantitative Easing is Now a Fixture, Not a Temporary Patch. 
http://www.investopedia.com/articles/investing/030716/quantitative-easingnow-fixture-not-temporary-patch.asp, Accessed on: 26 December, 2016.

Hayes, A. (2016b, February). Negative Interest Rates: 4 Unintended Consequences Available at: http://www.investopedia.com/articles/investing/022616/negativeinterest-rates-4-unintended-consequences.asp, Accessed on: 26 December, 2016

Johnston, M. (2015). Open Market Operations vs. Quantitative Easing. Investopedia, Available at: http://www.investopedia.com/articles/investing/093015/openmarket-operations-vs-quantitative-easing.asp, Accessed on: 26 December, 2016.

Kelley, D. J., Singer, S., \& Herrington, M. (2011). The global entrepreneurship monitor. 2011 Global Report, GEM 2011, 7.

Koranyi, B. Strupczewski, J. (2016). ECB could hit inflation target by late 2018, early 2019: Draghi. Available at: http://www.channelnewsasia.com/news/business/ecb-could-hit-inflation-targetby-late-2018-early-2019-draghi/3191104.html, Accessed on: 26 December, 2016.

Lautenschläger, S. (2015, March). How can prudential regulation foster growth? In speech at the Frankfurt Finance Summit, European Central Bank.

Mian, A., \& Sufi, A. (2008). The consequences of mortgage credit expansion: Evidence from the 2007 mortgage default crisis (No. w13936). National Bureau of Economic Research.

Poposka, K. Mihajloska, E. (2015). SME Start-ups prior and after the Financial Crisis: Evidence for EU Countries. LAMBERT Publishing.

Rajan, R. (2013, December). A step in the dark: unconventional monetary policy after the crisis. Andrew Crockett Memorial Lecture, BIS, Basel, 23.

Sibert A. (2013). Central Bank Exit Strategies. ECB, Monetary Dialogue, Directorate General For Internal Policies, Policy Department A: Economic And Scientific Policy, Available at: http://bookshop.europa.eu/en/exit-strategies-and-theimpact-on-the-euro-area-pbQA0214086/, Accessed on: 26 December, 2016

Weber, A. (2010, October). Monetary policy after the crisis: A European perspective. In Speech given at the Shadow Open Market Committee (SOMC) symposium, New York City (Vol. 12).

Wyplosz, C. (2013). Exit Strategies. ECB, Monetary Dialogue, Directorate General For Internal Policies, Policy Department A: Economic And Scientific Policy, Available at: http://bookshop.europa.eu/en/exit-strategies-and-the-impact-onthe-euro-area-pbQA0214086/, Accessed on: 26 December, 2016 